\title{
Energy balance and obesity: what are the main drivers?
}

\author{
Isabelle Romieu ${ }^{1} \cdot$ Laure Dossus $^{1} \cdot$ Simón Barquera $^{2} \cdot$ Hervé M. Blottière $^{3} \cdot$ Paul W. Franks $^{4} \cdot$ Marc Gunter $^{1} \cdot$ \\ Nahla Hwalla ${ }^{5}$ - Stephen D. Hursting ${ }^{6}$ - Michael Leitzmann ${ }^{7}$ - Barrie Margetts ${ }^{8}$ - Chizuru Nishida ${ }^{9}$ \\ Nancy Potischman ${ }^{10} \cdot$ Jacob Seidell $^{11} \cdot$ Magdalena Stepien $^{1} \cdot$ Youfa Wang $^{12} \cdot$ Klaas Westerterp $^{13}$. \\ Pattanee Winichagoon ${ }^{14}$ - Martin Wiseman ${ }^{15}$. Walter C. Willett ${ }^{16} \cdot$ On behalf of the IARC working group on \\ Energy Balance and Obesity
}

Received: 21 October 2016 / Accepted: 6 February 2017 / Published online: 17 February 2017

(c) The Author(s) 2017. This article is published with open access at Springerlink.com

\begin{abstract}
Purpose The aim of this paper is to review the evidence of the association between energy balance and obesity.

Methods In December 2015, the International Agency for Research on Cancer (IARC), Lyon, France convened a Working Group of international experts to review the evidence regarding energy balance and obesity, with a focus on Low and Middle Income Countries (LMIC).

Results The global epidemic of obesity and the double burden, in LMICs, of malnutrition (coexistence of
\end{abstract}

Isabelle Romieu

romieu@iarc.fr

1 Nutrition and Metabolism Section, International Agency for Research on Cancer, 150 cours Albert Thomas, 69372 Lyon Cedex 08, France

2 Centro de Investigación en Nutrición y Salud, Instituto Nacional de Salud Pública, Cuernavaca, Mexico

3 Micalis Institute, MGP MetagenoPolis, INRA, AgroParisTech, Université Paris-Saclay, Jouy-en-Josas, France

4 Genetic and Molecular Epidemiology Unit, Lund University Diabetes Centre, CRC, University hospital Malmö, Malmö, Sweden

5 Faculty of Agricultural and Food Science, American University of Beirut, Beirut, Lebanon

6 Department of Nutrition and the Nutrition Research Institute, The University of North Carolina, Chapel Hill, USA

7 Department of Epidemiology and Preventive Medicine, University of Regensburg, Regensburg, Germany

8 Faculty of Medicine, Southampton General Hospital, University of Southampton, Southampton, UK

9 Nutrition Policy and Scientific Advice (NPU), Department of Nutrition for Health and Development (NHD), World Health Organization (WHO), Geneva, Switzerland undernutrition and overnutrition) are both related to poor quality diet and unbalanced energy intake. Dietary patterns consistent with a traditional Mediterranean diet and other measures of diet quality can contribute to long-term weight control. Limiting consumption of sugar-sweetened beverages has a particularly important role in weight control. Genetic factors alone cannot explain the global epidemic of obesity. However, genetic, epigenetic factors and the microbiota could influence individual responses to diet and physical activity.

10 Office of the Associate Director, Applied Research Program, Division of Cancer Control and Population Sciences, National Cancer Institute, Bethesda, USA

11 Faculty of Earth and Life Sciences, Department of Health Sciences, University Amsterdam, Amsterdam, The Netherlands

12 Department of Epidemiology and Environmental Health, School of Public Health and Health Professions, Joint Appointments, School of Medicine and Biomedical Sciences, University at Buffalo, State University of New York, Buffalo, USA

13 NUTRIM School of Nutrition and Translational Research in Metabolism, Maastricht University, Maastricht, The Netherlands

14 Institute of Nutrition, Mahidol University Salaya, Nakhon Pathom, Thailand

15 World Cancer Research Fund International, London, UK

16 Department of Nutrition, Harvard T.H. Chan School of Public Health, Boston, USA 
Conclusion Energy intake that exceeds energy expenditure is the main driver of weight gain. The quality of the diet may exert its effect on energy balance through complex hormonal and neurological pathways that influence satiety and possibly through other mechanisms. The food environment, marketing of unhealthy foods and urbanization, and reduction in sedentary behaviors and physical activity play important roles. Most of the evidence comes from High Income Countries and more research is needed in LMICs.

Keywords Energy intake $\cdot$ Energy expenditure $\cdot$ Energy balance $\cdot$ Obesity $\cdot$ Satiety $\cdot$ Diet

\section{Introduction}

Obesity is defined as a state of excess adiposity that presents a risk to health such as increased risk of chronic diseases including cancer [1-3] and is the consequence of sustained positive energy balance over time. Factors that influence energy balance can be considered as relating to the host (i.e., people), the environment (the set of external factors to which people are exposed) and the vector (food and drink). These factors interact in a complex way to influence eating and drinking patterns as well as activity behaviors. While experienced at the individual level, their roots lie in policies and actions that determine the environment, which may be local, national or international [4]. Therefore, understanding the relation between energy balance and obesity is a challenge and a necessity to develop effective prevention programs and policies. The International Agency for Research on Cancer (IARC) of the World Health Organization (WHO) convened a Working Group Meeting in December 2015 to review evidence regarding energy balance and obesity, with a focus on Low and
Middle Income Countries (LMIC), and to tackle the following scientific questions:

1. Are the drivers of the obesity epidemic related only to energy excess and/or do specific foods or nutrients play a major role in this epidemic?

2. What are the factors that modulate these associations?

3. Which types of data and/or studies will further improve our understanding?

Each expert summarized the evidence from the literature on a specific topic in a written document that was reviewed by the IARC secretariat before the meeting and shared with the other participants (see list of topics in Table 1). Each topic was then briefly presented during the meeting and extensively discussed in plenary session with the other participants. A full report will be soon available on the IARC website. In this paper, we present a summary of the different topics that we addressed during the workshop and its conclusions and recommendations.

\section{Prevalence of overweight and obesity and double burden of malnutrition}

Obesity is now well recognized as a disease in its own right and overweight accounts for about $37 \%$ of the global burden of disease (2013) [5]. Obesity rates have been constantly increasing in the last thirty years with a worldwide prevalence that nearly doubled between 1980 and 2014 [2]. In $2014,39 \%$ of adults aged 18 years and older $(38 \%$ of men and $40 \%$ of women) were overweight [2]. In most parts of the world, women are more likely to be obese than men [2]. The prevalence of overweight and obesity tends to increase generally with the income level of the countries

Table 1 List of topics presented during the working group meeting

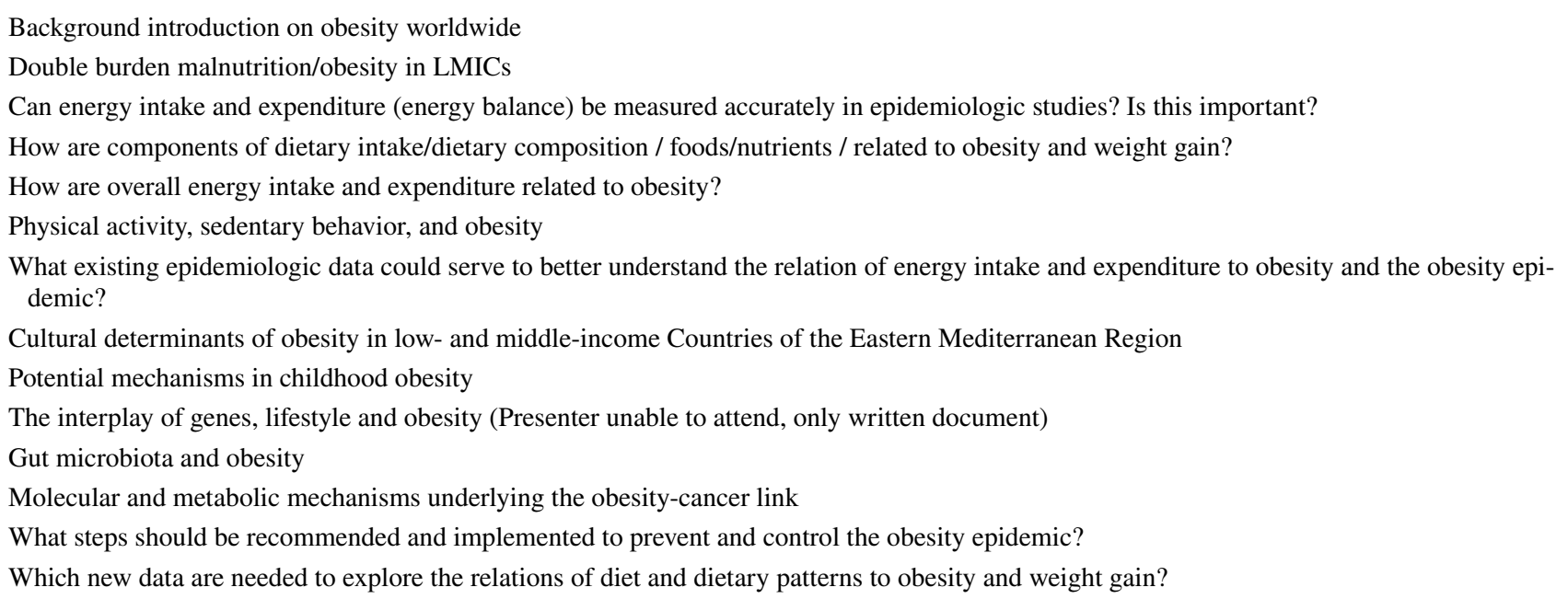


with the obesity prevalence in high-income and upper-middle-income countries being more than double that of lowincome countries [2] (Fig. 1). In 2014, there were 41 million overweight children under age 5 years in the world; about 10 million more than two decades ago [5, 6]. Recent data indicate that the prevalence of childhood obesity in some developed countries (e.g., some European countries and the US) has apparently reached a plateau [7-9]. However, the number of overweight children in Low and Middle Income Countries (LMICs) has more than doubled since 1990, from 7.5 to 15.5 million [10]. In 2014, almost half of all overweight children under 5 lived in Asia and one quarter lived in Africa [5, 6].

In many LMICs, obesity coexists with undernutrition (including energy, and macro and micronutrient deficiencies) leading to a "double burden of malnutrition" (DBMN) occurring across the life-course of individuals and coexisting in the same households and communities/countries [11]. There is a complex interplay between early undernutrition (in mothers before and during pregnancy, and in early childhood) and later overnutrition that exacerbates the risk of non-communicable diseases that are rising rapidly in LMICs [12, 13].

Rapid economic growth and urbanization in LMICs have resulted in changing traditional dietary patterns, with increasing consumption of highly processed foods and beverages containing less nutrient dense diets, replacing or supplementing traditional plant-based diets, and simultaneous increase in sedentary behaviors and reduction of physical activity across all ages [14-17]. Soft drinks (sodas, sugar-sweetened beverages, SSB) consumption volumes have been increasing in almost all countries [18]. Between 1996 and 2002, sales of processed (packaged) foods grew by $28 \%$ in LMICS, compared with only $2.5 \%$ in HICs.

\section{Determinants of energy balance: what the evidence tells us}

With recognition that overweight and obesity are major risk factors for cancer, cardiovascular disease, diabetes, and many other health conditions, the difference between energy intake and expenditure, frequently referred to as energy balance, has become of great interest because of its direct relation to long-term gain or loss of adipose tissue and alterations in metabolic pathways.

\section{Measurements of adiposity}

Several measures for overweight and obesity have been used in epidemiological studies [3]; however, it is important to be aware that such measures are imperfect markers of the internal physiological processes that are the actual determinants of cancer development.

BMI (the quotient between weight in kilograms and height in meters squared) is the most commonly used body composition marker in epidemiologic studies due to its simplicity of assessment, high precision and accuracy, but

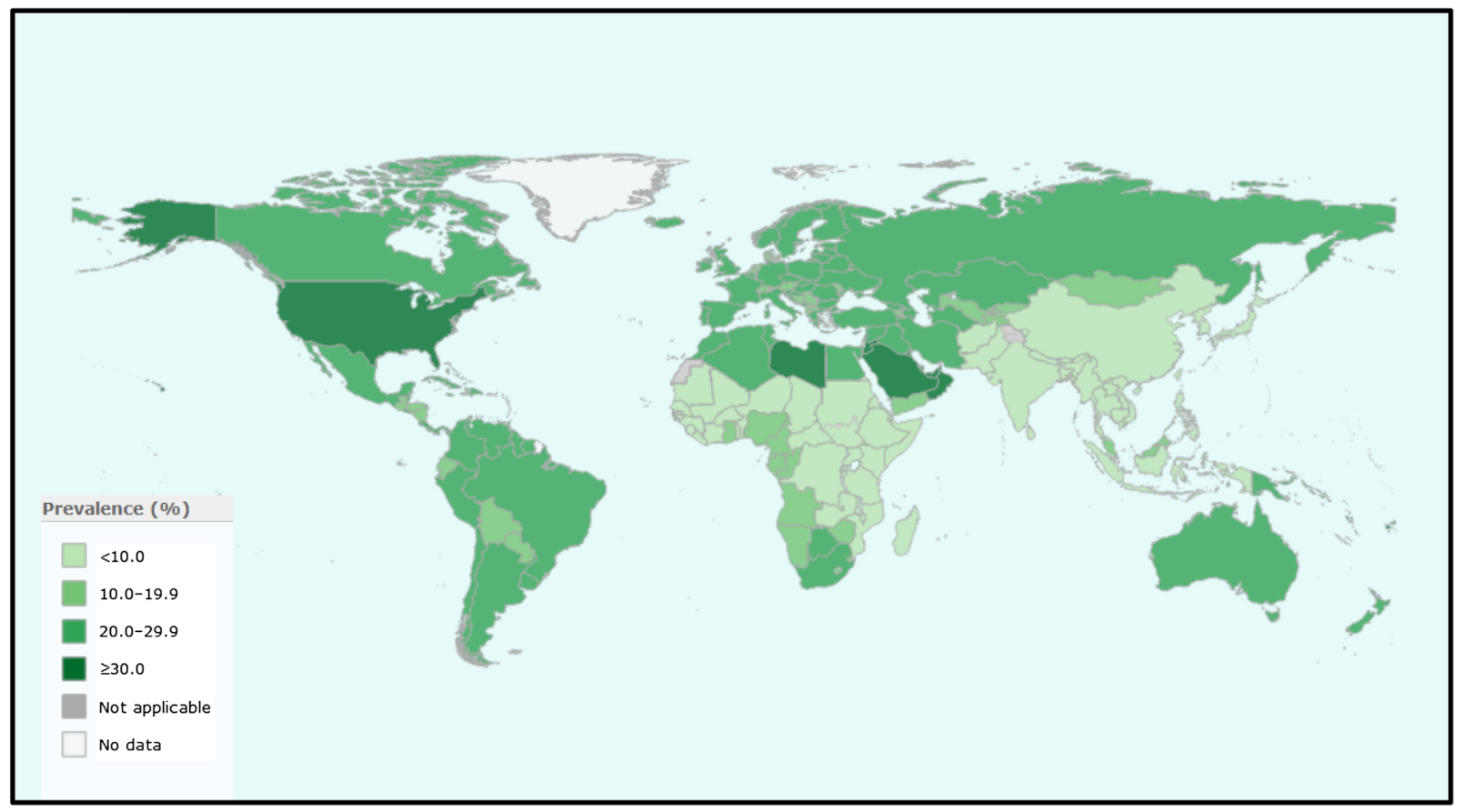

Fig. 1 Prevalence of obesity, ages 18+, both sexes, 2014 (age-standardized estimates)—-source: WHO 
it does not differentiate between lean and adipose tissue, or fat distribution, which varies across individuals, ethnicities, and throughout the lifespan. Nevertheless, BMI compares remarkably well to gold standard methods [24]. Waist circumference (WC) and waist-to-hip ratio (WHR) are useful to identify abdominal obesity but cannot clearly differentiate between visceral and subcutaneous fat compartments $[25,26]$. Other measures that can be used in medium- or large-scale studies include skinfold thickness and bioelectrical impedance analysis, although the latter appears to add little to measures based on weight and height [27]. More direct measures of body composition are available, such as air displacement plethysmography, underwater weighing (hydrodensitometry), dual-energy X-ray absorptiometry, ultrasound, computed tomography and magnetic resonance imaging [28, 29]. Although reproducible and valid [30], these measures of body composition are, due to high costs and lack of portability, limited to small-scale studies that require a high level of accuracy. Their use in large-scale epidemiologic studies tends to be as reference methods [31].

\section{Energy intake and energy expenditure}

Energy balance is the result of equilibrium between energy intake and energy expenditure. When energy intake exceeds expenditure, the excess energy is deposited as body tissue [1]. During adulthood, the maintenance of stable body weight depends on the energy derived from food and drink (energy intake) being equal to total energy expenditure over time. To lose body weight, energy expenditure must exceed intake, and to gain weight, energy intake must exceed expenditure [32]. Very small deviations from energy balance, on the order of $1-2 \%$ of daily energy intake, can result in large long-term changes in body weight $(\sim 20 \mathrm{~kg})$ [33].

Measuring dietary intake and energy expenditure is a challenge in epidemiology. Energy intake, in particular, besides sometimes considerable measurement error in its assessment, can be subject to selective biases, such as the tendency of overweight and obese people to underestimate their intake [27]. While some objective measures exist for assessing energy expenditure or physical activity [34], such tools are not available for energy intake. Thus, assessment of energy balance by calculating the difference between intake and expenditure is not practically useful in large scale population studies. When comparing four different methods of dietary assessment, Willett and colleagues have shown that for all measures of total energy expenditure or intake within person variability was high relative to the 1 or $2 \%$ difference between intake and expenditure that can be extremely important (personal communication). Over time the best practical marker of positive or negative energy balance is change in the body weight which is readily measured with high precision even by self-report [27]. Since body weight change cannot distinguish between loss or gain of lean or fat mass, interpretation of weight change in an individual rests on assumptions about the nature of tissues lost or gained if body composition is not measured directly [35]. However, for most people, weight gain over a period of years during adulthood is largely driven by gain in fat mass.

In conclusion, body weight and change in weight provide precise indicators of long-term deviations in energy balance and are widely available for epidemiology studies. These simple and inexpensive measures of energy balance can be used both as exposure and outcome variables, taking into consideration their other determinants and confounding factors. Although not useful for assessing energy balance, which requires extreme accuracy and precision, measures of energy intake and physical activity will continue to play other important roles in epidemiologic studies and in monitoring population trends.

\section{Understanding nutritional determinants of obesity}

Many factors relating to foods and beverages have been shown to influence amounts consumed or energy balance over the short to medium term, such as energy density and portion size [36, 37], although the effect of energy density over the longer term is unclear.

\section{Foods and dietary patterns}

One factor that has been suggested as being obesogenic is a high energy density of foods (i.e., an energy content of more than about 225-275 kcal per $100 \mathrm{~g}$ ) [38]. However, there are exceptions; for example, nuts and olive oil (both extremely energy dense) did not increase weight when added to a diet [39]. Fast foods are energy-dense micronutrient-poor foods often high in saturated and trans fatty acids, processed starches and added sugars [40]. Thus, the extent that these foods are obesogenic may be related to their composition rather than to their energy density. Several observational studies indicated a higher risk of obesity and weight gain in consumers of fast foods than in the non-consumers [41-44]. A recent study from the European Prospective Investigation into Cancer and Nutrition (EPIC) study reported that a high plasma level of industrial trans fatty acids, interpreted as biomarkers of dietary exposure to industrially processed foods, was associated with the risk of weight gain, particularly in women [45]. Evidence supporting an obesogenic effect of sugary drinks is strong, with high relevance to children, especially in low-income socioeconomic groups (consumption of SSB is $93 \%$ higher in low-income children 
than in high income children) [46] and LMICs (a 1\% rise in soft drink consumption was associated with an additional 3.4 overweight adults per 100 and 2.3 obese adults per 100 in LMICs) [47]. A meta-analysis of 22 cohort studies showed that each increment of sugary drink a day was associated with a 0.05-0.06 unit increase in BMI in children and $0.12-0.22 \mathrm{~kg}$ increased weight gain in adults [48]. Another meta-analysis of 5 cohort studies indicated a 55\% (32-82\%) higher risk of being overweight in children consuming sugary drinks daily [49]. Consumption of sweets and desserts characterized by high sugar content and energy density has been associated with weight gain [38], as well as red and processed meat (37\% increased risk of obesity for consumption of higher quantities of red and processed meat) [50]. Conversely, higher consumption of legumes, wholegrain foods including cereals, non-starchy vegetables, and fruits (which have relatively low energy density) as well as nuts (with high energy density) have been associated with a lower risk of obesity and weight gain [38]. The content of fiber, satiating effect of fat, and low glycemic index in many of these foods may play an important role.

Results from three U.S. cohorts indicated that better diet quality, i.e., higher scores on alternate Mediterranean Diet (MD) score, the Alternate Health Eating Index (HEI)-2010, and the Dietary Approaches to Stop Hypertension were associated with lower weight gain during adult life [51]. This was in agreement with the results obtained from European cohorts using similar indexes [52, 53]. A systematic review found, in 13 of 21 studies, a negative association between adherence to Mediterranean diet (MD) and overweight/obesity or weight gain (i.e., 29\% lower risk of being obese for men adhering to MD in a cohort study and up to $14 \mathrm{~kg}$ of weight lost after a 2-year MD intervention) [54].

Cohort studies conducted in LMICs would be valuable resources for understanding the impact of the nutrition and lifestyle transition on obesity. Some longitudinal studies have already been initiated in LMICs (as for instance the ones included in the Consortium of Health-Orientated Research in Transitioning Societies-COHORT [55], or the MTC cohort [56]). Building on these ongoing initiatives may prove informative and cost-efficient. Data from the Mexican Teacher cohort (MTC) have shown that women with a carbohydrates, sweet drinks and refined foods pattern were more at risk of having a larger silhouette and higher BMI, while a fruit and vegetable pattern was associated with a lower risk [57]. This emphasizes the need for public health interventions improving access to healthy diets, healthy food choices in the work place, and means of limiting consumption of beverages with a high sugar content and of highly processed foods, particularly those rich in refined starches.
Prevention of weight gain and/or maintenance of weight loss

Long-term experiments ( $>1$ year) on prevention of weight gain suggest that the change in body fatness that occurs with modifying intakes seems to be mediated via changes in energy intakes, since isoenergetic exchange of sugars with other carbohydrates was not associated with weight change [49]. Evidence from randomized trials conducted in children and adolescents indicates that consumption of sugar-sweetened beverages, as compared with non-calorically sweetened beverages, results in greater weight gain and increases in the body mass index; however, the evidence is limited to a small number of studies [58, 59]. The findings of these trials suggest that there is inadequate energy compensation (degree of reduction in intake of other foods or drinks), for energy delivered as sugar dissolved in water [58].

\section{Understanding weight loss}

In weight loss trials, low carbohydrate interventions led to significantly greater weight loss than did low-fat interventions when the intensity of intervention was similar [60]. In a 2-year trial, where obese subjects were randomly assigned to low-fat restricted calorie, Mediterranean restricted-calorie or low-carbohydrate-restricted calorie diet, weight loss was similar in the MD and lowcarb diet and significantly greater than in the low-fat diet. In their meta-analysis of $23 \mathrm{RCTs}$, Hu et al. [61] compared the effects of low-fat ( $\leq 30 \%$ energy) vs. low-carbohydrate ( $\leq 45 \%$ energy) diet and found that both types of diets resulted in comparable reductions in weight and waist circumference. However, compared with participants on low-fat diets, persons on low-carbohydrate diets experienced a slightly but statistically significantly lower reduction in total cholesterol and low-density lipoprotein cholesterol but a greater increase in high-density lipoprotein cholesterol and a greater decrease in triglycerides. The impact of reducing fat or carbohydrate may depend at least as much on the overall composition of the diet as on the reduction in the specific macronutrient targeted.

Most of these studies were conducted in HICs. This emphasizes the importance of conducting studies in LMICs in particular long-term dietary intervention trials focusing on alternative dietary patterns with foods readily available in these countries to propose viable changes in nutritional behaviors. 


\section{Factors that modulate the association between dietary intake and obesity}

\section{Physical activity}

Long-term observational studies fairly consistently show an association between physical activity and weight maintenance, and a 2009 position paper from the American College of Sports Medicine (ACSM) stated that 150-250 min per week of moderate intensity physical activity is effective to prevent weight gain [62]. The long-term effect of physical activity on weight loss has been less convincing and isolated aerobic exercise was not shown to be an effective weight loss therapy but may be effective in conjunction with diet [63]. Evidence suggests that diet combined with physical activity results in greater weight loss than diet alone and is more effective for increasing fat mass loss and preserving lean body mass and, therefore, it leads to a more desirable effect on overall body composition [64]. Weight maintenance after weight loss is improved with physical activity and $>250 \mathrm{~min}$ of physical activity per week has been recommended [62]. Intervention studies have consistently found no effect of resistance exercise on reducing body weight [62] or visceral adipose tissue [65]. However, resistance training appears to be more effective in increasing lean body mass than aerobic training and the combination of aerobic and resistance training may be the most efficient exercise training modality for weight loss [66]. In recent years, physical activity research has expanded its focus to include the potentially detrimental effects of sedentary behavior on energy balance. Findings from the Nurses' Health Study showed that time spent watching television viewing was positively related to risk of obesity (each 2-h/d increment in TV watching was associated with a $23 \%$ increase in obesity) [67]. Sedentary behavior also represents an independent risk factor for obesity in children and adolescents [68]. In short-term studies, higher levels of physical activity have been shown to mitigate the effect of increasing energy density on weight gain, and it appears that at the low levels of physical activity typical of current high income populations, adequate suppression of appetite to maintain energy balance is compromised [69].

In conclusion, moderate intensity physical activity performed for 150-250 min per week appears to prevent weight gain and produces modest weight loss in adults. Greater amounts of moderate intensity physical activity (>250 min per week) are required for weight maintenance following weight loss. Resistance exercise does not appear to decrease body weight or body fat but it promotes gain of lean body mass, and the combination of resistance and aerobic exercise seems to be optimal for weight loss. Physical activity improves chronic disease risk factors independent of its impact on body weight regulation. Moreover, sedentary behavior represents an independent risk factor for the development of overweight and obesity.

\section{Genetic and epigenetic factors}

The patterns and distributions of obesity within and between ethnically diverse populations living in similar and contrasting environments suggest that some ethnic groups are more susceptible than others to obesity [70]. More than 150 common genetic variants have been robustly associated with measures of body composition [71], though the individual impact of each variant is small. There is now convincing epidemiological evidence of interactions between common variants in the FTO (Fat mass and obesity-associated protein) gene and lifestyle with respect to obesity [72-74]. However, almost all these data are from cross-sectional studies, and temporal relationships are not clear. There are large studies supporting gene-lifestyle interactions at several other common loci, but the burden of evidence is far less for these loci than for FTO [75, 76]. However, the magnitude of the interaction effects reported for FTO (or other common variants) is insufficient to warrant the use of those data for clinical translation. Potentially reversible epigenetic changes in particular altered DNA methylation patterns could also serve as biomarkers of energy balance and mediators of gene-environment interaction in obesity [77]. Several 'epigenome-wide association studies' have now been conducted and have identified a panel of gene loci where methylation levels significantly differ in obese and lean individuals [78, 79]. Such discoveries could provide novel insights into how energy balance and its determinants influence obesity development, interaction with diet and environmental factors and subsequent metabolic dysregulation.

In summary, there is an abundance of published evidence, predominantly from cross-sectional epidemiological studies, that supports the notion that lifestyle and genetic factors interact to cause obesity. However, few studies have been adequately replicated, and functional validation and specifically designed intervention studies are rarely undertaken, both of which are necessary to determine whether observations of gene-lifestyle interaction in obesity are causal and of clinical relevance.

\section{Microbiota}

In a healthy symbiotic state, the colonic microbiota interacts with our food, in particular dietary fiber, allowing energy harvest from indigestible dietary compounds. It also interacts with cells, including immune cells, as well as with the metabolic and nervous systems; and protects against pathogens. Conversely, a dysbiotic state is often associated with diseases including not only inflammatory 
bowel diseases (IBD), allergy, colorectal cancer and liver diseases, but also obesity, diabetes and cardiovascular diseases [80]. Dysbiosis may be defined as an imbalanced microbiota including loss of keystone species, reduced richness or diversity, increased pathogens or pathobionts or modification or shift in metabolic capacities [81]. Dysbiosis in the intestinal microbiota has been associated with obesity [82]. A loss of bacterial gene richness is linked to more severe metabolic syndrome, and less sensitivity to weight loss following caloric restriction diet [83]. Dietary habits also seem to be associated with microbiota richness [84]. The proposed mechanisms by which gut microbiota dysbiosis and loss of richness can promote obesity and insulin resistance are diverse, often derived from mouse models, and still deserve more studies and validation in humans.

\section{Determinants of childhood obesity}

Many factors have contributed to the increase in the prevalence of obesity in children including unhealthy dietary patterns with high consumption of fast foods and highly processed food [85], of sugar sweetened beverages [86], lack of PA, an increase in sedentary behaviors (e.g., screen time) [87], and shorter sleep duration [88]. Other factors, such as changes in parenting and family factors, school factors, social norms, community food and PA environments that affect children's eating and PA have also contributed [89, 90]. Experiences during early life (e.g., prenatal factors such as the in utero exposures experienced and postnatal factors such as infant and young child feeding) can have an important, long-term impact on future health, including obesity risk [91]. In particular, maternal gestational weight gain (GWG) [92], maternal overweight prior to pregnancy, smoking during pregnancy, high or low infant birth weight, rapid weight gain during the first year of life [93-95], early obesity rebound [96], breastfeeding patterns [97] and early introduction of complementary food [98] have all been linked to later excess adiposity. Many of these are inter-related and work is ongoing to disentangle concurrent factors. In addition, high levels of stress during childhood and adolescence may change eating habits and augment consumption of highly palatable but nutrient-poor foods [99].

Multiple factors at the individual, family, school, society and global levels impact children's energy-balance-related behaviors, and have contributed to the increases in childhood obesity worldwide. Although genetic factors may play a role in affecting individuals' susceptibility of developing obesity, environmental factors should be the key targets of intervention efforts to fight the epidemic as they are modifiable.

\section{Prevention of obesity}

Numerous policy options to prevent obesity have been explored, and evidence is sufficient to conclude that many are cost effective. Given the multifactorial nature of obesity, as in other complex public health problems, a combination of interventions is more likely to generate better results than focusing only on a single measure [100]. Gortmaker et al. [101] estimated the cost-effectiveness of seven interventions that are generally considered to be most promising. They modeled the reach, costs and savings for the US population 2015-25. Some of these interventions (excise tax on sugar-sweetened beverages, elimination of tax deduction for advertising unhealthy food to children and nutrition standards for food and beverages sold in schools outside of meals) not only prevent many cases of childhood obesity, but also potentially cost less to implement than they would save for society.

The global childhood obesity epidemic demands a population-based multisector, multi-disciplinary, and culturally relevant approach. Children need protection from exploitative marketing and special efforts to support healthy eating, PA behaviors, and optimal body weight [102-104]. Adequate evidence has been accumulated that interventions, especially school-based programs, can be effective in preventing childhood obesity [105]. Preventing obesity will require sustained efforts across all levels of government and civil society.

Although there are individual differences in susceptibility, obesity is by large a societal problem resulting from health related behaviors that are largely driven by environmental upstream factors. Many options for policies to prevent obesity are available and many of these are effective and cost-effective. Integrated management of the epidemic of obesity requires top-down government policies and bottom-up community approaches and involvement of many sectors of society. Integrating evidence-based prevention and management of obesity is essential.

\section{The obesity-cancer link: what are the underlying mechanisms?}

There is convincing evidence for a role of obesity as a causal factor for many types of cancer including colorectum, endometrium, kidney, oesophagus, postmenopausal breast, gallbladder, pancreas, gastric cardia, liver, ovary, thyroid, meningioma, multiple myeloma, and advanced prostate cancers [19]. Recent progress on elucidating the mechanisms underlying the obesity-cancer connection suggests that obesity exerts pleomorphic effects on pathways related to tumor development and progression and, thus, there are potential opportunities for primary to tertiary 
prevention of obesity-related cancers. We now know that obesity can impact well-established hallmarks of cancer (such as genomic instability, angiogenesis, tumor invasion and metastasis and immune surveillance) [20]. However, obesity-associated perturbations in systemic metabolism and inflammation, and the interactions of these perturbations with cancer cell energetics, are emerging as the primary drivers of obesity-associated cancer development and progression. In both obesity and metabolic syndrome, alterations occur in circulating levels of insulin and insulin-like growth factors, sex hormones, adipokines, inflammatory factors, several chemokines, lipid mediators and vascular associated factors [21-23].

\section{Which types of data and /or studies will further improve our understanding?}

Most research on obesity and cancer has focused on Caucasians in HICs. While many of the identified risk factors in HICs will have the same physiologic effects in LMICs, the determinants may be different, in addition to other environmental and genetic differences across populations. Novel risk factors or traditional diets may be identified in newly studied populations and regions. Diet is shaped by many factors such as traditions, knowledge about diet, food availability, food prices, cultural acceptance, and health conditions. Likewise, a variety of factors will influence daily physical activity and sedentary behaviors, including dwellings, urbanization, opportunities for safe transportation by bicycle riding and walking, recreational facilities, employment constraints and health conditions. Surveillance of current diet and health conditions and assessment of trends over time is of major importance in LMICS. Further resources and research capacity are of highest priority.

In addition to surveillance efforts, prospective studies able to document lifestyle and change of lifestyle over time are an important area of research. Several cohort studies conducted in HICs have shown an impact of healthy dietary patterns on obesity [106] and similar studies could be conducted in LMICs to identify dietary patterns related to weight gain and obesity in a variety of settings to evaluate the major lifestyle, behavioral and policy influences in an effort to plan public health interventions appropriately. Intervention and implementation research in different countries/regions is needed to learn about social and physiological changes and the sustainability of the changes, in particular among children and adolescents in both schoolbased and non-school-based setting as well as research on the cost effectiveness of policies.

A major challenge is to capture life course exposures and identify windows of susceptibility. Early exposure to poor diet and sugar-sweetened beverages, sedentariness, tobacco smoke and other environmental exposures can alter infants' and children's growth patterns and may result in altered metabolism, obesity, and risk of chronic disease in adulthood [107]. Cohort studies covering the whole life course, focusing on critical windows of exposure and the time course of exposure to disease (birth cohorts, adolescent cohorts, and young adult cohorts), should be considered. Of particular interest are multicentered cohorts and inter-generational cohorts that would create resources to enable research on the interplay between genetics, lifestyle and the environment. For example in the Avon longitudinal study of parents and children (ALSPAC), increasing intake of energy-dense nutrient-poor foods during childhood (mostly free sugar) was associated with obesity development. Diets with higher energy density were associated with increased fat mass [108]. Most relevant to LMICs is the observation that children who were stunted in infancy and are subsequently exposed to more calories, at puberty, are more likely to have higher fat mass at the same BMI compared with children who were not stunted [93, 94, 109]. Poor maternal prenatal dietary intakes of energy, protein and micronutrients have been associated with increased risk of adult obesity in offspring while a high protein diet during the first 2 years of life was also associated with increased obesity later in life [110]; conversely, exclusive breastfeeding was associated with lower risk of obesity later in childhood, although this may not persist into adulthood [111]. Similar results from a cohort study conducted in Mexico show that children exclusively or predominantly breastfed for 3 months or more had lower adiposity at 4 years [112]. Further work on birth cohorts or other prospective studies in LMICs is likely to provide insights into the developmental causes of obesity and NCDs. Input from local research communities, health ministries and policy makers and appropriate funding or resource assignment are critical for the success of new efforts in LMICs.

There is clearly a need for capacity building and resources devoted to nutritional research in LMICs. The first step would be a comprehensive assessment of resources already in place, and the identification of gaps and priorities for moving forward. Repeated surveillance surveys are essential in LMICs for evaluation of current and future status of the population and addressing undesirable trends with prevention and control programs. It is recognized that few prospective studies are currently underway in LMICs and resources will be needed to pursue this important area of research. Input from local research communities, health ministries and policy makers are critical for the success of new efforts in LMICs. 


\section{Conclusions and recommendations}

The global epidemic of obesity and the double burden of malnutrition are both related to poor quality diet; therefore, improvement in diet quality can address both phenomena.

The benefits of a healthy diet on adiposity are likely mediated by effects of dietary quality on energy intake, which is the main driver of weight gain. Energy balance is best assessed by changes in weight or in fat mass. Measures of energy intake and expenditure are not precise enough to capture small differences that are of individual and public health importance. The quality of the diet may exert its effect on energy balance through complex hormonal and neurological pathways that influence satiety and possibly through other mechanisms.

Dietary patterns characterized by higher intakes of fruits and vegetables, legumes, whole grains, nuts and seeds and unsaturated fat, and lower intakes of refined starch, red meat, trans and saturated fat, and sugar-sweetened foods and beverages, consistent with a traditional Mediterranean diet and other measures of dietary quality, can contribute to long-term weight control. Limiting consumption of sugarsweetened beverages has a particularly important role in weight control. In weight loss trials, existing evidence does not support the role of the reduction in the percentage of energy from fat on weight loss, though the reductions in fat may not have been low enough for the outcome and the effects of single macronutrients cannot be adequately captured without specifying replacement/comparison sources of energy.

Genetic factors cannot explain the global epidemic of obesity. It is possible that factors such as genetic, epigenetic and the microbiota can influence individual responses to diet and physical activity. Very few gene-diet interactions or diet-microbiota have been established in relation to obesity and effects on cancer risk.

Short-term studies have not provided clear benefit of physical activity for weight control, but meta-analysis of longer term trials indicates a modest benefit on body weight loss and maintenance. The combination of aerobic and resistance training seems to be optimal. Long-term epidemiologic studies also support modest benefits of physical activity on body weight. This includes benefits of walking and bicycle riding, which can be incorporated into daily life and be sustainable for the whole population. Physical activity also has important benefit on health outcomes independent of its effect on body weight. In addition, long-term epidemiologic studies show that sedentary behavior (in particular TV viewing) is related to increased risk of obesity, suggesting that limiting sedentary time has potential for prevention of weight gain.

The major drivers of the obesity epidemic are the food environment, marketing of unhealthy foods and beverages, urbanization, and probably reduction in physical activity. Existing evidence on the relations of diet, physical activity and socio-economic and cultural factors to body weight is largely from HICs. There is an important lack of data on diet, physical activity and adiposity in most parts of the world and this information should to be collected in a standardized manner when possible. In most environments, $24 \mathrm{~h}$ recalls will be the more suitable method for dietary surveillance. Attention should be given to data in subgroups because mean values may obscure important disparities. In utero and early childhood, environment has important implications for lifetime adiposity. This offers important windows of opportunity for intervention. Observational data on determinants of body weight and intervention trials across the life course to improve body weight are also required. To accomplish these goals, there is a need for resources to build capacity and conduct translational research.

Gaining control of the obesity epidemic will require the engagement of many sectors including education, healthcare, the media, worksites, agriculture, the food industry, urban planning, transportation, parks and recreation, and governments from local to national. This provides the opportunity for all individuals to participate in this effort, whether at home or in establishing high-level policy. We now have evidence that intensive multi-sector efforts can arrest and partially reverse the rise of obesity in particular among children. In conclusion, we are gaining understanding on the determinants of energy balance and obesity and some of these findings are being translated into public health policy changes. However, further research and more action from policy makers are needed.

Open Access This article is distributed under the terms of the Creative Commons Attribution 4.0 International License (http:// creativecommons.org/licenses/by/4.0/), which permits unrestricted use, distribution, and reproduction in any medium, provided you give appropriate credit to the original author(s) and the source, provide a link to the Creative Commons license, and indicate if changes were made.

\section{References}

1. Anderson AS, Key TJ, Norat T, Scoccianti C, Cecchini M, Berrino $\mathrm{F}$ et al. European code against cancer 4th edition: obesity, body fatness and cancer. Cancer Epidemiol. 2015

2. World Health Organization (2014) Global status report on noncommunicable diseases: World Health Organization, Geneva. http://apps.who.int/iris/bitstr eam/10665/148114/1/9789241564854_eng.pdf?ua=1

3. World Cancer Research Fund/American Institute for Cancer Research (2007) Food, nutrition, physical activity, and the prevention of cancer: a global perspective. AICR, Washington DC

4. World Cancer Research Fund/American Institute for Cancer Research (2009) Policy and action for cancer prevention. Food, nutrition, and physical activity: a global perspective 
5. Ng M, Fleming T, Robinson M, Thomson B, Graetz N, Margono $\mathrm{C}$ et al (2014) Global, regional, and national prevalence of overweight and obesity in children and adults during 19802013: a systematic analysis for the Global Burden of Disease Study 2013. Lancet 384(9945):766-781

6. de Onis M, Blossner M, Borghi E (2010) Global prevalence and trends of overweight and obesity among preschool children. Am J Clin Nutr 92(5):1257-1264

7. Lobstein T, Jackson-Leach R, Moodie ML, Hall KD, Gortmaker SL, Swinburn BA et al (2015) Child and adolescent obesity: part of a bigger picture. Lancet 385(9986):2510-2520

8. Wabitsch M, Moss A, Kromeyer-Hauschild K (2014) Unexpected plateauing of childhood obesity rates in developed countries. BMC Med 12:17

9. Wang YF, Baker JL, Hil JO, Dietz WH (2012) Controversies regarding reported trends: has the obesity epidemic leveled off in the United States? Adv Nutr 3(5):751-752

10. United Nations Children's Fund World Health Organization, The World Bank. Levels and trends in child malnutrition UNICEF-WHO-World Bank Group joint child malnutrition estimates: key findings of the 2015 edition 2015. http://www. who.int/nutgrowthdb/jme_brochure2015.pdf?ua $=1$.

11. Shrimpton R, Rokx C (2012) The double burden of malnutrition : a review of global evidence. Health, Nutrition and Population (HNP) discussion paper. World Bank, Washington DC

12. Darnton-Hill I, Nishida C, James WP (2004) A life course approach to diet, nutrition and the prevention of chronic diseases. Public Health Nutr 7(1a):101-121

13. James $P$ et al (2000). Ending malnutrition by 2020: an agenda for change in the Millennium. UN SCN, Geneva

14. Moubarac JC, Martins AP, Claro RM, Levy RB, Cannon G, Monteiro CA (2013) Consumption of ultra-processed foods and likely impact on human health. Evidence from Canada. Public Health Nutr 16(12):2240-2248

15. Monteiro CA, Levy RB, Claro RM, de Castro IR, Cannon G (2011) Increasing consumption of ultra-processed foods and likely impact on human health: evidence from Brazil. Public Health Nutr 14(1):5-13

16. Baker P, Friel S (2014) Processed foods and the nutrition transition: evidence from Asia. Obes Rev 15(7):564-577

17. Barquera S, Pedroza-Tobias A, Medina C (2016) Cardiovascular diseases in mega-countries: the challenges of the nutrition, physical activity and epidemiologic transitions, and the double burden of disease. Curr Opin Lipidol 27(4):329-344

18. International Food Policy Research Institute (2015). Global nutrition report 2015: actions and accountability to advance nutrition and sustainable development. Washington, DC

19. Lauby-Secretan B, Scoccianti C, Loomis D, Grosse Y, Bianchini F, Straif K et al (2016) Body fatness and cancer-viewpoint of the IARC Working Group. N Engl J Med 375(8):794-798

20. Hanahan D, Weinberg RA (2011) Hallmarks of cancer: the next generation. Cell 144(5):646-674

21. Bonomini F, Rodella LF, Rezzani R (2015) Metabolic syndrome, aging and involvement of oxidative stress. Aging disease 6(2):109-120

22. Hursting SD, Berger NA (2010) Energy balance, host-related factors, and cancer progression. J Clin Oncol 28(26):4058-4065

23. Renehan AG, Roberts DL, Dive C (2008) Obesity and cancer: pathophysiological and biological mechanisms. Arch Physiol Biochem 114(1):71-83

24. Sun Q, van Dam RM, Spiegelman D, Heymsfield SB, Willett WC, Hu FB (2010) Comparison of dual-energy X-ray absorptiometric and anthropometric measures of adiposity in relation to adiposity-related biologic factors. Am $\mathrm{J}$ Epidemiol 172(12):1442-1454
25. World Health Organization (2011) Waist circumference and waist-hip ratio: a report of a WHO expert consultation

26. van der Kooy K, Leenen R, Seidell JC, Deurenberg P, Droop A, Bakker CJ (1993) Waist-hip ratio is a poor predictor of changes in visceral fat. Am J Clin Nutr 57(3):327-333

27. Willett W. Implications of total energy intake for epidemiologic analyses. Nutritional epidemiology. 3rd edn. Oxford University Press, New York, pp 260-286

28. Heymsfield SB, Lohman TG, Wang Z, Going SB (2005) Human body composition. 2nd edn. Champaign

29. McCrory MA, Gomez TD, Bernauer EM, Mole PA (1995) Evaluation of a new air displacement plethysmograph for measuring human body composition. Med Sci Sports Exerc 27(12):1686-1691

30. Glickman SG, Marn CS, Supiano MA, Dengel DR (2004) Validity and reliability of dual-energy X-ray absorptiometry for the assessment of abdominal adiposity. J Appl Physiol (1985) 97(2):509-514

31. Bandera EV, Maskarinec G, Romieu I, John EM (2015) Racial and ethnic disparities in the impact of obesity on breast cancer risk and survival: a global perspective. Adv Nutr 6(6):803-819

32. Scientific Advisory Committee on Nutrition (2011) Dietary reference values for energy. The Stationery Office, London

33. Hall KD, Sacks G, Chandramohan D, Chow CC, Wang YC, Gortmaker SL et al (2011) Quantification of the effect of energy imbalance on bodyweight. Lancet 378(9793):826-837

34. Healy GN, Wijndaele K, Dunstan DW, Shaw JE, Salmon J, Zimmet PZ et al (2008) Objectively measured sedentary time, physical activity, and metabolic risk: the Australian Diabetes, Obesity and Lifestyle Study (AusDiab). Diabetes Care 31(2):369-371

35. Romero-Corral A, Somers VK, Sierra-Johnson J, Thomas RJ, Collazo-Clavell ML, Korinek J et al (2008) Accuracy of body mass index in diagnosing obesity in the adult general population. Int J Obes (Lond) 32(6):959-966

36. Ello-Martin JA, Ledikwe JH, Rolls BJ (2005) The influence of food portion size and energy density on energy intake: implications for weight management. Am J Clin Nutr 82(1 Suppl):236 S-241 S

37. Prentice AM (1998) Manipulation of dietary fat and energy density and subsequent effects on substrate flux and food intake. Am J Clin Nutr 67(3 Suppl):535 S-541 S

38. Fogelholm M, Anderssen S, Gunnarsdottir I, Lahti-Koski M (2012) Dietary macronutrients and food consumption as determinants of long-term weight change in adult populations: a systematic literature review. Food Nutr Res 56

39. Salas-Salvado J, Bullo M, Babio N, Martinez-Gonzalez MA, Ibarrola-Jurado N, Basora $\mathbf{J}$ et al (2011) Reduction in the incidence of type 2 diabetes with the Mediterranean diet: results of the PREDIMED-Reus nutrition intervention randomized trial. Diabetes Care 34(1):14-19

40. Jaworowska A, Blackham T, Davies IG, Stevenson L (2013) Nutritional challenges and health implications of takeaway and fast food. Nutr Rev 71(5):310-318

41. Schroder H, Fito M, Covas MI (2007) Association of fast food consumption with energy intake, diet quality, body mass index and the risk of obesity in a representative Mediterranean population. Br J Nutr 98(6):1274-1280

42. Pereira MA, Kartashov AI, Ebbeling CB, Van Horn L, Slattery ML, Jacobs DR Jr., et al (2005) Fast-food habits, weight gain, and insulin resistance (the CARDIA study): 15-year prospective analysis. Lancet 365(9453):36-42

43. Alkerwi A, Crichton GE, Hebert JR (2014) Consumption of ready-made meals and increased risk of obesity: findings from the observation of cardiovascular risk factors in Luxembourg (ORISCAV-LUX) study. Br J Nutr 1-8 
44. Kant AK, Whitley MI, Graubard BI (2015) Away from home meals: associations with biomarkers of chronic disease and dietary intake in American adults, NHANES 2005-2010. Int J Obes (Lond) 39(5):820-827

45. Chajes V, Biessy C, Ferrari P, Romieu I, Freisling H, Huybrechts I et al (2015) Plasma elaidic acid level as biomarker of industrial trans fatty acids and risk of weight change: report from the EPIC study. PloS one 10(2):e0118206

46. Han E, Powell LM (2013) Consumption patterns of sugarsweetened beverages in the United States. J Acad Nutr Dietetics 113(1):43-53

47. Basu S, McKee M, Galea G, Stuckler D (2013) Relationship of soft drink consumption to global overweight, obesity, and diabetes: a cross-national analysis of 75 countries. Am J Public Health 103(11):2071-2077

48. Malik VS, Pan A, Willett WC, Hu FB (2013) Sugar-sweetened beverages and weight gain in children and adults: a systematic review and meta-analysis. Am J Clin Nutr 98(4):1084-1102

49. Te Morenga L, Mallard S, Mann J (2013) Dietary sugars and body weight: systematic review and meta-analyses of randomised controlled trials and cohort studies. BMJ 346:e7492

50. Rouhani MH, Salehi-Abargouei A, Surkan PJ, Azadbakht L (2014) Is there a relationship between red or processed meat intake and obesity? A systematic review and meta-analysis of observational studies. Obes Rev 15(9):740-748

51. Fung TT, Pan A, Hou T, Chiuve SE, Tobias DK, Mozaffarian $\mathrm{D}$ et al (2015) Long-term change in diet quality is associated with body weight change in men and women. J Nutr 145(8):1850-1856

52. Romaguera D, Norat T, Vergnaud AC, Mouw T, May AM, Agudo A et al (2010) Mediterranean dietary patterns and prospective weight change in participants of the EPIC-PANACEA project. Am J Clin Nutr 92(4):912-921

53. Funtikova AN, Benitez-Arciniega AA, Gomez SF, Fito M, Elosua R, Schroder H (2014) Mediterranean diet impact on changes in abdominal fat and 10-year incidence of abdominal obesity in a Spanish population. Br J Nutr 111(8):1481-1487

54. Buckland G, Bach A, Serra-Majem L (2008) Obesity and the Mediterranean diet: a systematic review of observational and intervention studies. Obes Rev Off J Int Assoc Study Obes 9(6):582-593

55. Richter LM, Victora CG, Hallal PC, Adair LS, Bhargava SK, Fall $\mathrm{CH}$ et al (2012) Cohort profile: the consortium of healthorientated research in transitioning societies. Int $\mathrm{J}$ Epidemiol 41(3):621-626

56. Lajous M, Ortiz-Panozo E, Monge A, Santoyo-Vistrain R, Garcia-Anaya A, Yunes-Diaz E et al (2015) Cohort Profile: The Mexican Teachers' Cohort (MTC). Int J Epidemiol

57. Romieu I, Escamilla-Nunez MC, Sanchez-Zamorano LM, Lopez-Ridaura R, Torres-Mejia G, Yunes EM et al (2012) The association between body shape silhouette and dietary pattern among Mexican women. Public Health Nutr 15(1):116-125

58. Scientific Advisory Committee on Nutrition (2015) Carbohydrates and health. The Stationery Office, London

59. Mirza NM, Palmer MG, Sinclair KB, McCarter R, He J, Ebbeling CB et al (2013) Effects of a low glycemic load or a low-fat dietary intervention on body weight in obese Hispanic American children and adolescents: a randomized controlled trial. Am J Clin Nutr 97(2):276-285

60. Tobias DK, Chen M, Manson JE, Ludwig DS, Willett W, Hu FB (2015) Effect of low-fat diet interventions versus other diet interventions on long-term weight change in adults: a systematic review and meta-analysis. Lancet Diabetes. Endocrinol 3(12):968-979

61. Hu T, Mills KT, Yao L, Demanelis K, Eloustaz M, Yancy WS Jr., et al (2012) Effects of low-carbohydrate diets versus low-fat diets on metabolic risk factors: a meta-analysis of randomized controlled clinical trials. Am J Epidemiol 176(Suppl 7):S44-S54

62. Donnelly JE, Blair SN, Jakicic JM, Manore MM, Rankin JW, Smith BK et al (2009) American College of Sports Medicine Position Stand. Appropriate physical activity intervention strategies for weight loss and prevention of weight regain for adults. Med Sci Sports Exerc 41(2):459-471

63. Thorogood A, Mottillo S, Shimony A, Filion KB, Joseph L, Genest $\mathbf{J}$ et al (2011) Isolated aerobic exercise and weight loss: a systematic review and meta-analysis of randomized controlled trials. Am J Med 124(8):747-755

64. Miller CT, Fraser SF, Levinger I, Straznicky NE, Dixon JB, Reynolds J et al (2013) The effects of exercise training in addition to energy restriction on functional capacities and body composition in obese adults during weight loss: a systematic review. PloS one 8(11):e81692

65. Ismail I, Keating SE, Baker MK, Johnson NA (2012) A systematic review and meta-analysis of the effect of aerobic vs. resistance exercise training on visceral fat. Obes Rev Off J Int Assoc Study Obesity 13(1):68-91

66. Schwingshackl L, Dias S, Strasser B, Hoffmann G (2013) Impact of different training modalities on anthropometric and metabolic characteristics in overweight/obese subjects: a systematic review and network meta-analysis. PLoS One 8(12):e82853

67. Hu FB, Li TY, Colditz GA, Willett WC, Manson JE (2003) Television watching and other sedentary behaviors in relation to risk of obesity and type 2 diabetes mellitus in women. Jama 289(14):1785-1791

68. Liao Y, Liao J, Durand CP, Dunton GF (2014) Which type of sedentary behaviour intervention is more effective at reducing body mass index in children? A meta-analytic review. Obes Rev Off J Int Assoc Study Obesity 15(3):159-168

69. Blundell JE, Gibbons C, Caudwell P, Finlayson G, Hopkins M (2015) Appetite control and energy balance: impact of exercise. ObesRev 16(Suppl 1):67-76

70. Franks PW, Ravussin E, Hanson RL, Harper IT, Allison DB, Knowler WC et al (2005) Habitual physical activity in children: the role of genes and the environment. Am J Clin Nutr 82(4):901-908

71. Locke AE, Kahali B, Berndt SI, Justice AE, Pers TH, Day FR et al (2015) Genetic studies of body mass index yield new insights for obesity biology. Nature 518(7538):197-206

72. Ahmad S, Varga TV, Franks PW (2013) Gene x environment interactions in obesity: the state of the evidence. Hum Hered 75(2-4):106-115

73. Kilpelainen TO, Qi L, Brage S, Sharp SJ, Sonestedt E, Demerath E et al (2011) Physical activity attenuates the influence of FTO variants on obesity risk: a meta-analysis of 218,166 adults and 19,268 children. PLoS Med 8(11):e1001116

74. Qi Q, Chu AY, Kang JH, Jensen MK, Curhan GC, Pasquale LR et al (2012) Sugar-sweetened beverages and genetic risk of obesity. N Engl J Med 367(15):1387-1396

75. Franks PW, Christophi CA, Jablonski KA, Billings LK, Delahanty LM, Horton ES et al (2014) Common variation at PPARGC1A/B and change in body composition and metabolic traits following preventive interventions: the Diabetes Prevention Program. Diabetologia 57(3):485-490

76. Nettleton JA, Follis JL, Ngwa JS, Smith CE, Ahmad S, Tanaka $\mathrm{T}$ et al (2015) Gene x dietary pattern interactions in obesity: analysis of up to 68,317 adults of European ancestry. Hum Mol Genet 24(16):4728-4738

77. van Dijk SJ, Tellam RL, Morrison JL, Muhlhausler BS, Molloy PL (2015) Recent developments on the role of epigenetics in obesity and metabolic disease. Clinical Epigenetics 7(1):66 
78. Chambers JC, Loh M, Lehne B, Drong A, Kriebel J, Motta V et al. Epigenome-wide association of DNA methylation markers in peripheral blood from Indian Asians and Europeans with incident type 2 diabetes: a nested case-control study. Lancet Diabetes Endocrinol 3(7):526-534

79. Dick KJ, Nelson CP, Tsaprouni L, Sandling JK, Aïssi D, Wahl $\mathrm{S}$ et al. DNA methylation and body-mass index: a genome-wide analysis. Lancet. 383(9933):1990-1998

80. Blottiere HM, de Vos WM, Ehrlich SD, Dore J (2013) Human intestinal metagenomics: state of the art and future. Curr Opin Microbiol 16(3):232-239

81. Vangay P, Ward T, Gerber JS, Knights D (2015) Antibiotics, pediatric dysbiosis, and disease. Cell Host Microbe 17(5):553-564

82. Le Chatelier E, Nielsen T, Qin J, Prifti E, Hildebrand F, Falony $\mathrm{G}$ et al (2013) Richness of human gut microbiome correlates with metabolic markers. Nature 500(7464):541-546

83. Dao MC, Everard A, Aron-Wisnewsky J, Sokolovska N, Prifti E, Verger EO et al (2016) Akkermansia muciniphila and improved metabolic health during a dietary intervention in obesity: relationship with gut microbiome richness and ecology. Gut 65(3):426-436

84. Kong LC, Holmes BA, Cotillard A, Habi-Rachedi F, Brazeilles $\mathrm{R}$, Gougis S et al (2014) Dietary patterns differently associate with inflammation and gut microbiota in overweight and obese subjects. PLoS One 9(10):e109434

85. Lobstein T, Baur L, Uauy R, TaskForce IIO (2004) Obesity in children and young people: a crisis in public health. Obes Rev 5(Suppl 1):4-104

86. Perez-Morales E, Bacardi-Gascon M, Jimenez-Cruz A (2013) Sugar-sweetened beverage intake before 6 years of age and weight or BMI status among older children; systematic review of prospective studies. Nutr Hosp 28(1):47-51

87. Robinson TN (1999) Reducing children's television viewing to prevent obesity: a randomized controlled trial. JAMA 282(16):1561-1567

88. Fatima Y, Doi SAR, Mamun AA (2015) Longitudinal impact of sleep on overweight and obesity in children and adolescents: a systematic review and bias-adjusted meta-analysis. Obes Rev 16(2):137-149

89. Lobstein T, Jackson-Leach R, Moodie ML, Hall KD, Gortmaker SL, Swinburn BA et al (2015) Child and adolescent obesity: part of a bigger picture. Lancet

90. WHO (2004) Global strategy on diet, physical activity and health - what are the causes? World Health Organization

91. ISDOHaD. International Society for Developmental Origins of Health and Disease

92. Tie HT, Xia YY, Zeng YS, Zhang Y, Dai CL, Guo JJ et al (2014) Risk of childhood overweight or obesity associated with excessive weight gain during pregnancy: a meta-analysis. Arch Gynecol Obstet 289(2):247-257

93. Norris SA, Osmond C, Gigante D, Kuzawa CW, Ramakrishnan L, Lee NR et al (2012) Size at birth, weight gain in infancy and childhood, and adult diabetes risk in five low- or middle-income country birth cohorts. Diabetes Care 35(1):72-79

94. Adair LS, Martorell R, Stein AD, Hallal PC, Sachdev HS, Prabhakaran D et al (2009) Size at birth, weight gain in infancy and childhood, and adult blood pressure in 5 low- and middleincome-country cohorts: when does weight gain matter? Am J Clin Nutr 89(5):1383-1392
95. de Beer M, Vrijkotte TG, Fall CH, van Eijsden M, Osmond C, Gemke RJ (2015) Associations of infant feeding and timing of linear growth and relative weight gain during early life with childhood body composition. Int J Obes (Lond) 39(4):586-592

96. Papadimitriou A (2015) Timing of adiposity rebound and prevalence of obesity. J Pediatr 167(2):498

97. Weng SF, Redsell SA, Swift JA, Yang M, Glazebrook CP (2012) Systematic review and meta-analyses of risk factors for childhood overweight identifiable during infancy. Arch Dis Child 97(12):1019-1026

98. Pearce J, Taylor MA, Langley-Evans SC (2013) Timing of the introduction of complementary feeding and risk of childhood obesity: a systematic review. Int J Obesity 37(10):1295-1306

99. Wilson SM, Sato AF (2014) Stress and paediatric obesity: what we know and where to go Stress. Health (London) 30(2):91-102

100. Cecchini M, Sassi F, Lauer JA, Lee YY, Guajardo-Barron $\mathrm{V}$, Chisholm D. Tackling of unhealthy diets, physical inactivity, and obesity: health effects and cost-effectiveness. Lancet. 376(9754):1775-1784

101. Gortmaker SL, Long MW, Resch SC, Ward ZJ, Cradock AL, Barrett JL et al (2015) Cost effectiveness of childhood obesity interventions: evidence and methods for CHOICES. Am J Prev Med 49(1):102-111

102. Pan American Health Organization (2011) Recommendations from a Pan American Health Organization Expert Consultation on the Marketing of Food and Non-Alcoholic Beverages to Children in the Americas. PAHO, Washington, D.C.

103. Jenkin G, Madhvani N, Signal L, Bowers S (2014) A systematic review of persuasive marketing techniques to promote food to children on television. Obes Rev 15(4):281-293

104. Hawkes C (2007) Regulating and litigating in the public interest: regulating food marketing to young people worldwide: trends and policy drivers. Am J Public Health 97(11):1962-1973

105. Wang YWY, Wilson RF, Bleich S, Cheskin L, Weston C, Showell N, Fawole O, Lau B, Segal J (2013) Childhood obesity prevention programs: comparative effectiveness review and metaanalysis internet: agency for healthcare research and quality (US); 2013. Contract No.: 13-EHC081-EF

106. USDA Nutrition Evidence Library (NEL) (2014) Dietary patterns systematic review

107. UK Scientific Advisory Committee on Nutrition (2011) The influence of maternal, fetal and child nutrition on development of chronic disease in later life

108. Emmett PM, Jones LR (2015) Diet, growth, and obesity development throughout childhood in the Avon Longitudinal Study of Parents and Children. Nutr Rev 73(Suppl 3):175-206

109. Victora CG, Adair L, Fall C, Hallal PC, Martorell R, Richter $\mathrm{L}$ et al (2008) Maternal and child undernutrition: consequences for adult health and human capital. Lancet 371(9609):340-357

110. Yang Z, Huffman SL (2013) Nutrition in pregnancy and early childhood and associations with obesity in developing countries. Matern Child Nutr 9(Suppl 1):105-119

111. Michels KB, Willett WC, Graubard BI, Vaidya RL, Cantwell MM, Sansbury LB et al (2007) A longitudinal study of infant feeding and obesity throughout life course. Int J Obes (Lond) 31(7):1078-1085

112. Ramirez-Silva I, Rivera JA, Trejo-Valdivia B, Martorell R, Stein $\mathrm{AD}$, Romieu I et al (2015) Breastfeeding status at age 3 months is associated with adiposity and cardiometabolic markers at age 4 years in Mexican children. J Nutr 145(6):1295-1302 